The BDJ News section accepts items that include general news, latest research and diary events that interest our readers. Press releases or articles may be edited, and should include a colour photograph if possible.

Please direct your correspondence to the News Editor, Arveen Bajaj at the BDJ, 64 Wimpole Street WIG 8YS or by e-mail to bdj@bda.org

\section{Straight to your desk top}

$B D J$ readers can now get regular updates from the journal live via rich site summaries (RSS) feeds. An RSS feed is a text file that usually contains details about the most recent entries on a website.

The $B D J$ 's RSS feed supplies headlines, links and article summaries from the latest issue of the $B D J$. Other websites can then incorporate these headlines into their pages automatically. You can also view the RSS feed using a desktop reader, software that can display your favourite RSS feeds directly on your computer. There are probably over a million RSS feeds from news websites, webloggers and other sources published on the Internet each day.

This makes checking out your favourite sites like the $B D J$ site quick and easy and it regularly fetches the latest version of the RSS file. For more information contact Helen King, h.king@ @ature.com, or visit www.nature.com/bdj/rss.rdf.

\section{Staff subjected to phone abuse}

The recent publicity surrounding the case of a dental surgery in Wales generating a queue of around 300 people who wanted to register with an NHS dentist highlighted the shortage of NHS dental practitioners in rural areas.

However, the incident also showed a more sinister side when staff at the practice were subject to abusive phone calls.

Brynteg Dental Practice in Carmarthen took on an extra 300 patients after advertising its NHS list, but more than 300 people were turned away after the list became full. Staff at the practice started to receive complaints and abusive phone calls, and have been given police support on how to deal with the calls. A hotline has also been set up to the local police station. The surgery says it may reopen its books in December or January but may operate a waiting list in order to avoid a repeat of the recent situation.

\section{Eyes on the prize}

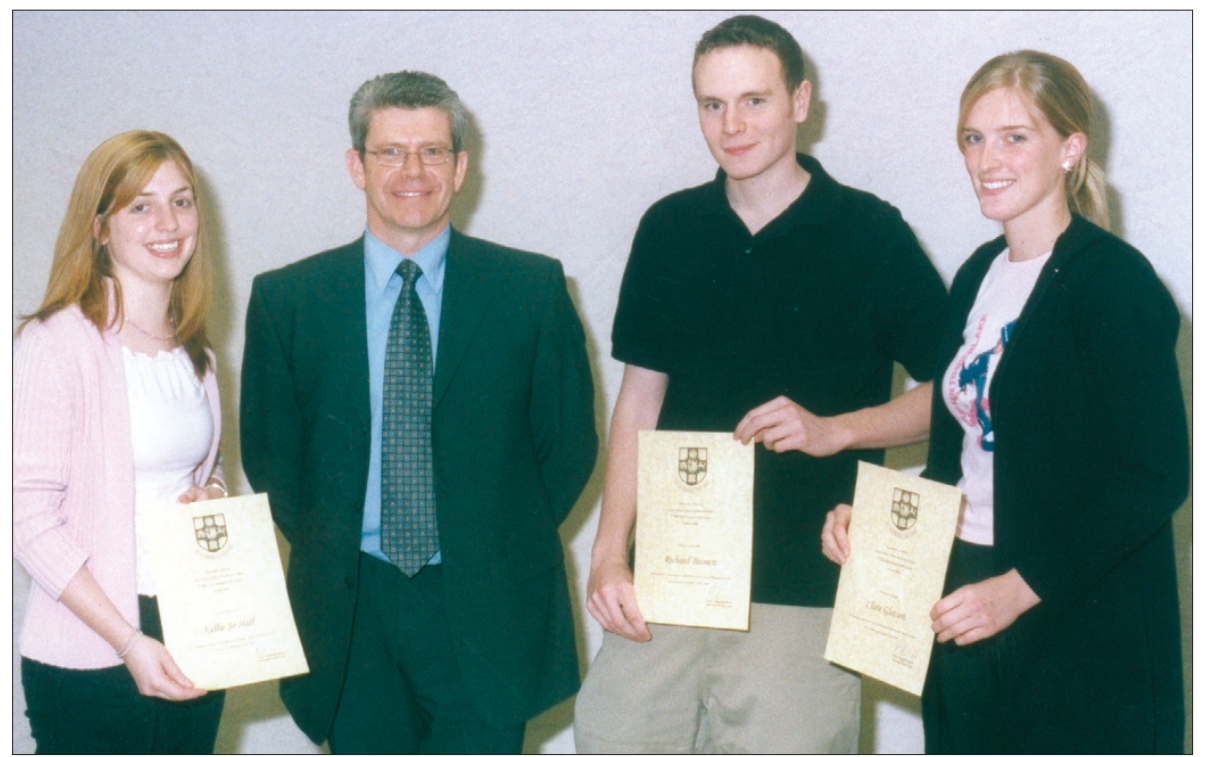

Three students from the University of Bristol Dental School were recently presented with this year's Heraeus Kulzer Biomaterials Prize in recognition of their outstanding performance in the Basic Biomaterials section of their five year Bachelor of Dental Science (BDS) course. Of the total of 51 students who completed the course this year, the top three were Clare Gleeson who won first place, Richard Brown in second place and Kellie Jo Hall in third place. They were presented with their awards by managing director of Heraeus Kulzer, Peter Higginbotham. (From left to right: Kellie Jo Hall, Peter Higginbotham, Richard Brown and Clare Gleeson)

\section{Dentaid launches new website}

Dentaid, the specialist charity that recycles used dental equipment for use in the developing world, has launched its totally revamped and upgraded website.

The pages include sections on fundraising, volunteering and equipment donations. For dentists or laboratories that are considering equipment donations, the website lists the items required and full details of the proce-

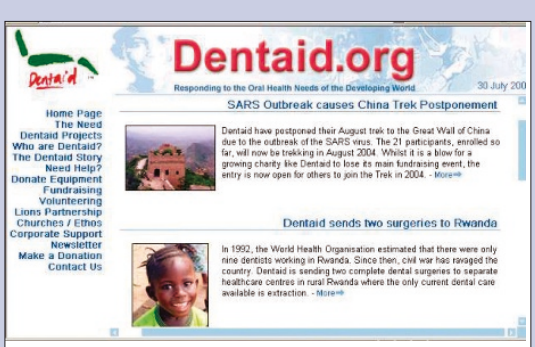

The home page of the new Dentaid website dure to follow. The need throughout the world for dental resources is clearly outlined, followed by Dentaid projects already completed and plotted onto a world map.

There is also a section on 'The Dentaid story', a description of the beginnings of the charity from its inception following a visit to a Ukraine prison, to the present day with its workshops sending out surgeries to 33 countries to date. For those who would like to help in a practical capacity, the volunteering page offers ideas from sorting instruments to links to overseas dentistry opportunities. Visit www.dentaid.org for more information. 


\section{DIARY}

September 2003

BDA Young Dentist Conference Scotland

Date: 13.09 .03

Venue: Hilton Dunblane Hydro

Contact: BDA Scotland

Tel: 01738441040

Fax: 01738441042

E-mail: bda.scotland@bda.org

BDA - Running a safe practice

Date: 18.09 .03

Venue: Holiday Inn Leeds / Brighouse Contact: Kath Blackler, Events Office

Tel: 02075634590

E-mail: www.bda-events.org

The Faculty of General Dental Practitioners (UK) - Preservative Dentistry: Is less more?

Date: 25.09 .03

Venue: Manchester

Tel: 01612756600

www.den.man.ac.uk

The British Practice Managers Association Annual Conference

Date: 26-27.09.03

Venue: Bath

Contact: BDPMA Head Office

Tel: 08708400381

Annual Meeting of the International Society for the Prevention of Tobacco Induced

Diseases

Date: 29.09.03-01.10.03

Venue: Winnipeg, Canada

Contact: PTID-Society (Congress 2003)

Fax: +1 (204) 789-3913

E-mail: ptidsociety@aol.com
Winning team

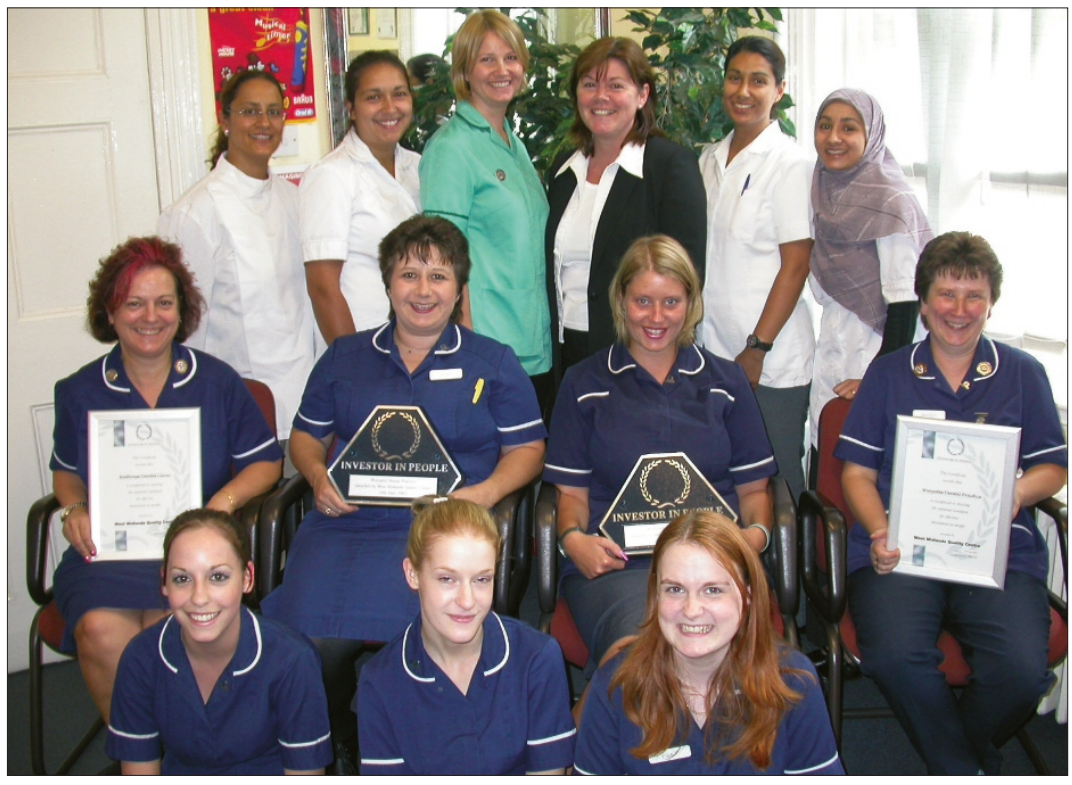

Redditch dental practices Redhouse Dental Clinic and Winyates Dental Practice have been recognised as Investors in People. Husband and wife team Dr Dinesh Phakkey and Dr Sarbjit Phakkey (back row, far left) jointly run the practices with the help of their manager Sue Marshall (back row, third from right) and a team of four dentists, 11 nurses and reception staff and two hygienists.

\section{New appointment at Eastman}

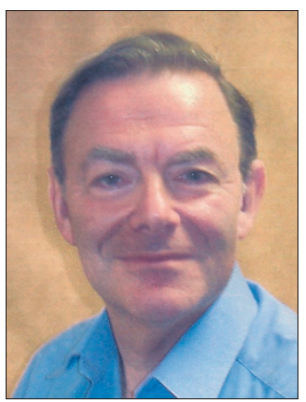

Dr Maurice Faigenblum
Eastman Continuing Professional Development has announced the appointment of Maurice Faigenblum as Senior Lecturer in Restorative Dentistry and Specialist in Prosthodontics.

Dr Faigenblum is supervising the joint BDJ/Eastman CPD project (www.bdjeastmancpd.com) and is also responsible for developing national and international distance learning study groups which will be launched in early 2004 .

He started his academic career at The Royal Dental Hospital, subsequently transferring to UCH and Guys.

He migrated into full time NHS general practice in the late 60s and in 1974 became a part-time member of staff in the Department of Prosthetic Dentistry at the Eastman Dental Hospital and Institute. 


\section{Education firsts}

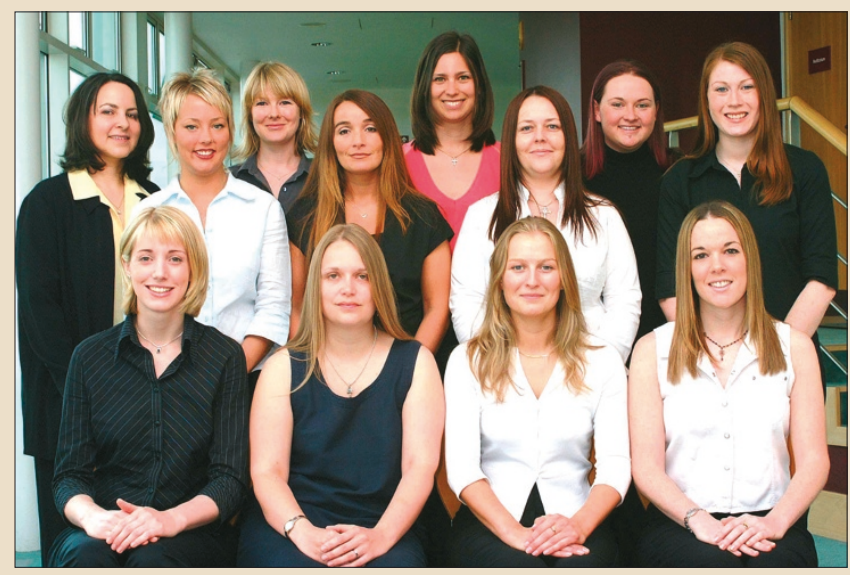

The first graduates to qualify from University Dental Hospital of Manchester's BSc degree recorded a one hundred per cent success rate. The graduates will be employed both as hygienists and therapists.

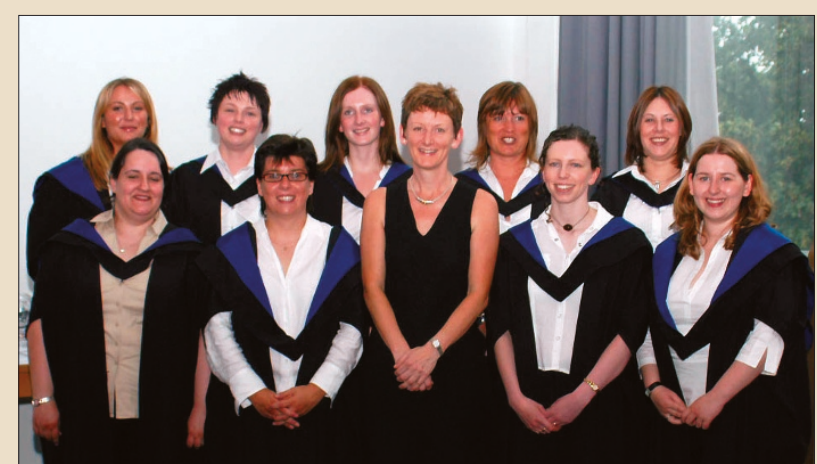

Oral hygiene graduates celebrated their achievement of the first award of the Diploma of Dental Hygiene from the University of Dundee. The two year programme taught at the Dundee Dental Hospital and School has an intake of ten students and all graduates have been successful in finding posts in the UK. The diploma in Dundee is the only university awarded diploma in Scotland and one of only 12 in the UK.

Dental nurse Lindsey Baker, (right) from the IDH Clarendon Road Dental Practice in Hinckley, is one of the first dental nurses in Leicestershire to receive the National Vocational Qualification in Dental Nursing. Lindsey gained her NVQ from the examining board for dental nurses after 15 months of training. This qualification is not yet available in Leicestershire, so for Lindsey to achieve her NVO a tutor came from Coventry to take her through the 14 units. To complete the course Lindsey had to sit a final exam and undergo an open assessment at work. She can now use her qualification as a foundation for study in specialist fields such as sedation or radiography, or to move on to become a hygienist.

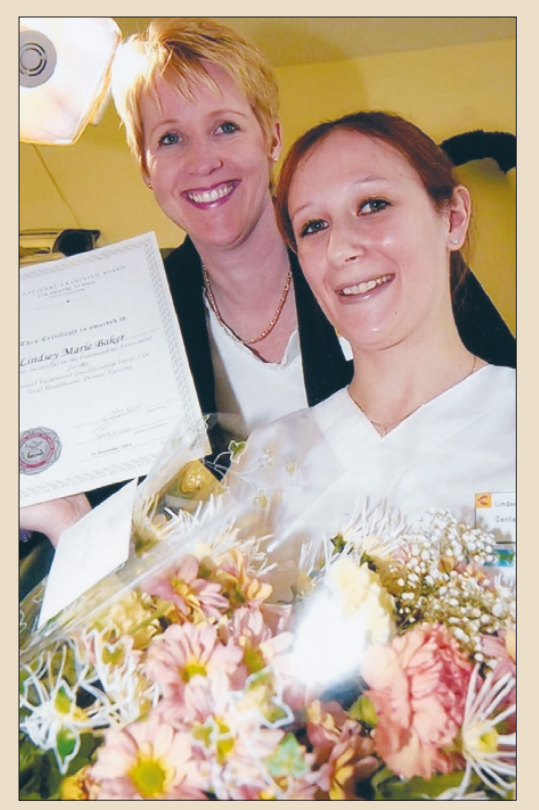

